ARTIGO

Recebido em:

$21 / 10 / 2015$

Aceito em:

$26 / 02 / 2016$

\title{
Temáticas em biblioteconomia e ciência da informação no Brasil: enfoque nos periódicos científicos eletrônicos ${ }^{1}$ Topics in library and information science in Brazil: focus on electronic scientific journals
}

Marina Alves de MENDONÇA

Bibliotecária da Universidade Federal do Ceará - marinamendoncace@gmail.com

\section{Resumo}

Destaca os periódicos científicos eletrônicos nacionais de biblioteconomia e ciência da informação com objetivo de identificar as temáticas mais debatidas em ciência da informação, por meio da análise dos artigos publicados de 2003 a 2013, além de detectar os temas dos artigos analisados visando conceber semelhanças e diferenças temáticas no âmbito da interdisciplinaridade, incluindo a identificação dos "vazios", ou seja, de temas importantes e não contemplados. Incluem-se as revistas de biblioteconomia em virtude de parte dos títulos relevantes atualmente originarem-se de publicações antes dedicadas à biblioteconomia e que, após, concentraram-se em estudos de ciência da informação. Para consecução desta pesquisa de abordagem quali-quantitativa, natureza descritiva e concepção de estudo de caso, recorrem-se à análise documental e análise de conteúdo temática como técnicas de coleta e análise de dados, respectivamente. Verifica-se que o incremento da pesquisa nesse campo acompanha a expansão dos Programas de Pós-Graduação em Ciência da Informação e se expande à medida que encontra nos periódicos eletrônicos, os meios para intensificar a comunicação científica e ratificar relações interdisciplinares. Registram-se 48 categorias temáticas, dentre elas, Gestão apresenta incidência mais elevada (191 artigos) em contraposição às classes Administração; e Meio Ambiente e Sustentabilidade, ambas com apenas sete estudos, cada. Biblioteconomia aparece com o maior número de relações interdisciplinares. Recomenda-se que pesquisadores da área voltem sua aten ção a temas em ascensão ainda pouco explorados no âmbito da ciência da informação, a exemplo de Estudos Cognitivos e Comportamentais; e Arquitetura da Informação, haja vista as perspectivas de crescimento e de contribuição ao campo.

Palavras-chave: Ciência. Comunicação científica. Periódicos científicos eletrônicos.

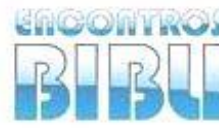

v. 21, n. 46,2016 p. 81-103

ISSN 1518-2924
1 Artigo originado da dissertação de mestrado intitulada "Periódicos científicos eletrônicos nacionais de biblioteconomia e ciência da informação: estudos produzidos entre 2003 e 2013", Universidade Federal da Paraíba, ano de defesa 2015. 


\begin{abstract}
Accents the national electronic journals of library and information science with purpose of identifying the questions most debated in information science through the analysis of articles published from 2003 to 2013, in addition to detecting the subjects of the articles analyzed in order to detect thematic similarities and differences in the scope of interdisciplinarity, including the identification of "empty", i.e. important issues not contemplated. Include the library science journals for the reason of the relevant titles currently be originated of publications before dedicated to the library science and then concentrated on studies in information science. To achieve this quali-quantitative research, nature descriptive and case study, resort to documentary analysis and thematic content analysis as collection techniques and data analysis, respectively. Verifies that the increase in research in this field follows with the expansion of the Graduate Program in Information Science and expands as found in electronic journals, the means to intensify scientific communication and ratify interdisciplinary relations. Registers 48 themes, among which Management has the highest incidence (191 articles) as opposed to the classes; Administration and Environment and Sustainability, both with only seven studies each. Library Science has the highest number of interdisciplinary relations. It is recommended that researchers in the field turn their attention to topics on the rise not yet explored in the context of information science, like Cognitive and Behavioral Studies; and Information Architecture, in view of the prospects for growth and contribution to the field.
\end{abstract}

Keywords: Science. Scientific communication. Electronic scientific journals.

\title{
1 INTRODUÇÃO
}

É de conhecimento inconteste que os periódicos (ou revistas) integram a categoria formal de comunicação científica. Neste sentido, Silva, Correia e Lima (2010, p. 220) reforçam:

0 registro formal possibilita que a pesquisa e seus resultados fiquem acessíveis à comunidade científica e garanta propriedade intelectual aos pesquisadores quanto às descobertas científicas. Na pesquisa, a comunicação é necessária para que, através da avaliação realizada pelos pares da produção científica, o conhecimento produzido seja validado de alguma forma, fazendo com que o sistema social da ciência mantenha sua dinâmica.

Os periódicos registram vasta produção de conhecimento científico, bem como fomentam o aperfeiçoamento das pesquisas. No decorrer do tempo, as revistas, em sua condição de fontes de informação, sofrem mudanças profundas e as próprias instituições de ensino superior e institutos de pesquisa se tornam mais rigorosos em busca da qualidade dos conteúdos veiculados. Para tanto, as instituições acadêmicas e de fomento à pesquisa estabelecem parâmetros e indicadores para as publicações científicas, especialmente os periódicos, por sua relevância no circuito acadêmico e científico. Afinal, são eles imprescindíveis ao desenvolvimento, à discussão e ao aperfeiçoamento da ciência.

Os critérios mais importantes, que ajudam a delinear seu grau de contribuição para as respectivas áreas de conhecimento, são: qualidade dos artigos publicados e corpo editorial; critérios de arbitragem dos textos; natureza do órgão publicador / editor; abrangência; difusão da revista; indexação em base de dados; normalização e padronização; regularidade e periodicidade.

Neste tocante, os títulos eletrônicos vêm apresentando elevado crescimento em termos quantitativos, em especial, em algumas áreas, como a biblioteconomia e a ciência da informação (CI). As facilidades tecnológicas, a otimização de recursos financeiros e a visibilidade alcançada na divulgação das pesquisas são fatores que contribuem para tal incremento. Entende-se, que a produção científica de qualquer 
campo de conhecimento perpassa intrinsecamente pela qualidade de seus periódicos, uma vez que eles retratam o avanço da investigação científica das distintas áreas.

É óbvio que o avanço de qualquer área demanda informações de qualidade e de credibilidade, e, por conseguinte, passíveis de método avaliativo sistemático e objetivo. Avaliações e análises do que se convenciona chamar "fazer ciência" contribuem na busca não somente pela excelência como também pela superioridade das publicações. Trabalhos científicos refletem o status quo das áreas, questionam suas "verdades", avaliam sua evolução, com o intento de colaborar o avanço da área. Deste modo, é importante não apenas executar pesquisas nos diferentes campos de conhecimento, como também entender como a ciência da informação vem se desenvolvendo, seus delineamentos e suas possibilidades.

Destarte, este artigo trata dos periódicos científicos eletrônicos nacionais de biblioteconomia e ciência da informação. Trata-se do relato de uma pesquisa de abordagem quali-quantitativa e de natureza descritiva, cujo estudo de caso refere-se aos estudos produzidos entre 2003 e 2013. Evidencia-se parte da pesquisa referendada, cujas perguntas centrais são: quais temáticas têm se configurado como objeto de pesquisa nos periódicos científicos eletrônicos de biblioteconomia e CI brasileira? Quais as áreas de conhecimento que mais contribuem para a produção científica nos periódicos brasileiros? Quais tipos de relações interdisciplinares ocorrem entre os objetos de pesquisa neles envolvidos com o campo da CI brasileira?

Em face das questões enunciadas, objetiva-se identificar as temáticas mais debatidas em ciência da informação, por meio da análise dos artigos publicados no mencionado período; e, detectar os temas dos artigos analisados visando conceber semelhanças e diferenças temáticas no âmbito da interdisciplinaridade, incluindo a identificação dos "vazios", ou seja, de temas importantes e não contemplados. Enfocam-se os periódicos de biblioteconomia e CI, entendendo que são áreas com particularidades, mas que se relacionam intimamente conforme declara a Tabela de Áreas do Conhecimento da Capes [Coordenação de Aperfeiçoamento de Pessoal de Nível Superior] (2012), cuja a biblioteconomia é contemplada como subcampo da ciência da informação juntamente com teoria da informação; teoria geral da informação; processos da comunicação; representação da informação; teoria da classificação; métodos quantitativos, bibliometria; técnicas de recuperação de informação; processos de disseminação da informação; arquivologia; organização de arquivos. Ademais, parte dos títulos relevantes atuais são oriundos de publicações antes dedicadas especificamente à biblioteconomia e que, em seguida, concentraram-se na CI.

Assim, o presente artigo aborda os seguintes aspectos: periódicos científicos contemplando a biblioteconomia e CI no Brasil (seção 2); concepções e traços característicos dos periódicos científicos (seção 3); detalhamento dos procedimentos metodológicos do estudo (seção 4); identificação das temáticas em $\mathrm{CI}$, número de artigos relacionados às categorias e áreas de conhecimento interdisciplinar propiciadas pela análise de conteúdo (seções 5, 6 e 7); semelhanças e diferenças temáticas no âmbito da interdisciplinaridade (seção 8); e, por fim, as considerações finais do estudo (seção 9).

\section{PERIÓDICOS CIENTÍFICOS NO ÂMBITO DA BIBLIOTECONOMIA E CIÊNCIA DA INFORMAÇÃO NO BRASIL}

Nos anos 70, século passado, surgem os primeiros periódicos científicos brasileiros em biblioteconomia e CI, coincidindo, segundo Bufrem (2006), com o marco da pós-graduação stricto sensu no Brasil. Nesse período, registra-se a instalação de seis cursos de Mestrado em CI e áreas correlatas no país. A este 
respeito, Andrade e Oliveira (2005) destacam o surgimento de dois títulos, ano 1972: Ciência da Informação (sob a responsabilidade do Instituto Brasileiro de Informação em Ciência e Tecnologia, IBICT) e a Revista da Escola de Biblioteconomia da UFMG [Universidade Federal de Minas Gerais]. Este segundo título, em 1996, ganha a designação de Perspectivas em Ciência da Informação, sob a responsabilidade editorial da Escola de Ciência da Informação / UFMG. Além desses dois títulos, Miranda (2002) inclui no grupo pioneiro de periódicos, a Revista de Biblioteconomia de Brasília (encargo da Universidade de Brasília, UnB) e a Revista de Biblioteconomia e Documentação da FEBAB, título original, quando como publicação da Federação Brasileira de Associações de Bibliotecários, Cientistas da Informação e Instituições.

Nas décadas seguintes, anos 80 e 90 do século XX, ampliam-se os cursos de pós-graduação, responsáveis pelo incremento da literatura científica, que incorpora as revistas científicas, à época, majoritariamente, impressas. A evolução das revistas é determinada por transformações tecnológicas e o consequente crescimento da comunidade científica e, por conseguinte, de sua produção intelectual.

Araújo e Bufrem (2008) ratificam que os periódicos têm sua evolução marcada, em especial, por fatores de ordem material. Com as tecnologias de informação e comunicação (TIC), concretiza-se o conceito de periódico eletrônico, o qual favorece a produção, a disseminação e o acesso facilitado à informação. Isto porque, com a inserção de publicações científicas no ambiente eletrônico, sobretudo as revistas, passam a ser exploradas de forma diferente, porém sem perder sua validação em termos de conteúdo.

Os primeiros periódicos eletrônicos datam da década de 90 e no decorrer dos últimos anos adquirem mais aceitabilidade e respeitabilidade da comunidade científica. Acredita-se que tal fato se deve ao movimento na comunidade acadêmica pelo livre acesso ao conhecimento. A este respeito, Bomfá e Castro (2004) alertam que a transposição pura e simples de uma mídia impressa para o ambiente digital não é garantia de publicação de qualidade. Targino e Garcia (2008a, p. 35) complementam essa ideia, ao tratarem da responsabilidade ética e social na produção dos periódicos científicos:

[...] no lastro da citada globalização e da explosão das tecnologias de informação, que afeta, de forma radical, todos os segmentos da vida social, na atualidade, os dilemas éticos, mais do que antes, atingem a produção intelectual e / ou científica dos indivíduos das distintas áreas de conhecimento. Há mais facilidade de divulgação dos novos saberes e de acesso às informações, rompendo barreiras espaciais e geográficas, mas, em contraposição, a sagacidade e astúcia para fraudes se fazem mais presentes [...] na academia e em qualquer outra instância.

0 aspecto ético-social é importante para a progressão da ciência e deve estar presente na produção acadêmica, pois ajuda a conferir qualidade às pesquisas, e, por conseguinte, às publicações. A natureza eletrônica facilita, ao mesmo tempo, a produção, o acesso e a recuperação de informações, assim como apresenta vantagens em relação aos títulos impressos nos seguintes aspectos: expressivo grau de acesso livre; velocidade na avaliação dos estudos; facilidade na manutenção das coleções; menor custo com impressão e distribuição; tendência maior para manter a regularidade da publicação. Afinal, antes do surgimento desses títulos no ambiente eletrônico, os periódicos apresentam certas ocorrências, que restringem o alcance junto ao público-alvo, o que propicia sua aceitação em, praticamente, todas as áreas de conhecimento.

Estima-se que a aceitação dos periódicos eletrônicos deve-se à proliferação de títulos nos últimos 60 anos, cuja expansão ocasiona reavaliação de acervos e espaços de armazenamento. Nesta conjuntura ora descrita, os investimentos são 
deslocados da manutenção de coleções físicas nas bibliotecas para a promoção de recursos que objetivem o acesso virtual com o fim explícito de ampliar o alcance desses recursos. Exemplo consolidado é o Portal de Periódicos da Capes, cujo vasto acervo disponível inclui somente de periódicos mais de 35 mil títulos com texto completo. Assim, o governo federal brasileiro oferta maior número de títulos às bibliotecas institucionais, o que permite minimizar as disparidades econômicas regionais que alcançam o campo informacional.

Não obstante variações que afetam áreas mais conservadoras, à semelhança do Direito, que mantêm, ainda, títulos nos formatos impresso e eletrônico ou prosseguem apenas com o suporte impresso (o que não ocorre mais em biblioteconomia e CI), os títulos eletrônicos destacam-se como fonte relevante de informações e com irrestrita aceitação.

\section{PERIÓdICOS CIENTÍFICOS ELETRÔNICOS: CONCEPÇÕES E TRAÇOS CARACTERÍSTICOS}

Independentemente do formato em que se apresente, o periódico tem, entre outras, a função de registrar e difundir o conhecimento científico. Contudo, caracteriza-se por aspectos que o distingue de outras publicações periódicas, como seu processo editorial e a revisão por pares, além de manter indicadores de citação, autoria, coautoria e acesso. São itens que permitem às revistas fomentarem avaliação mais rigorosa da produção científica de pesquisadores e das instituições num campo determinado de conhecimento.

O estudo efetivado por Correia, Alvarenga e Garcia (2012) demonstra que os artigos publicados em periódicos científicos constituem elementos fundamentais para mensurar a produtividade docente dos programas de pós-graduação. A Capes, responsável pelos cursos de pós-graduação stricto sensu no Brasil, estimula e pressiona os professores a publicarem nas revistas qualificadas pela agência de fomento, ou seja, que possuam conceito Qualis, utilizando a produção como importante parâmetro quantitativo na avaliação dos programas. Em relação ao Qualis, a agência afirma, ano 2014a:

[...] é o conjunto de procedimentos utilizados [...] para estratificação da qualidade da produção intelectual dos programas de pósgraduação. Tal processo foi concebido para atender as necessidades específicas do sistema de avaliação [...] Como resultado, disponibiliza uma lista com a classificação dos veículos utilizados pelos programas de pós-graduação para a divulgação da sua produção [...] Dessa forma, o Qualis afere a qualidade dos artigos e de outros tipos de produção, a partir da análise da qualidade dos veículos de divulgação, ou seja, periódicos científicos. A classificação de periódicos é realizada pelas áreas de avaliação e passa por processo anual de atualização [...] Esses veículos são enquadrados em estratos indicativos da qualidade - $\mathrm{A} 1$, o mais elevado; A2; B1; B2; B3; B4; B5; C - com peso zero.

Embora possua papel relevante àquilo que se propõe, membros da comunidade científica manifestam-se a respeito de algumas inconsistências em tal processo de avaliação. Embora se reconheça a legitimidade das discussões em torno da melhoria do Qualis, é ele o principal instrumento de avaliação nacional para as revistas científicas. Ademais, os periódicos eletrônicos facilitam os processos. Gonçalves, Ramos e Castro (2006) elucidam que o fluxo editorial de uma revista científica compreende as seguintes etapas, aqui arroladas de forma concisa: recebimento de trabalhos para publicação; pré-seleção dos trabalhos; seleção de revisores; encaminhamento e acompanhamento da revisão por pares; contato com 
autores sobre comentários dos revisores, aprovação ou rejeição para publicação; revisão de texto; revisão gráfica; publicação.

Apesar de manter como meta a qualidade e, portanto, a avaliação como passo imprescindível, o processo editorial hoje realizado por meios eletrônicos, possui maior celeridade. Todavia, como visto no dia a dia, os artigos submetidos eletronicamente ainda podem esperar meses para sua avaliação, circunstância que, por vezes, prejudica a atualidade dos estudos.

Reitera-se que a sistemática adotada na avaliação dos artigos é a revisão por pares ou peer review. Consiste na análise acurada do artigo submetido a dois ou mais especialistas integrantes da comunidade científica, que podem indicar alterações e / ou melhorias ao trabalho por meio da emissão de parecer favorável ou contrário à publicação do mesmo. Embora esse sistema seja amplamente adotado é questionado pelos pesquisadores, devido ao tempo investido, à submissão a opiniões contrárias ou contraditórias e / ou à incompatibilidade de interesses. Na realidade, não obstante o estudo permanente de outros métodos que possam substituir o sistema de avaliação vigente, ainda não há outro procedimento metodológico com a mesma anuência por parte dos membros da comunidade científica. Targino e Garcia (2008b, p. 65) ressaltam que:

\footnotetext{
Todos os cuidados acerca da peer review para as revistas científicas impressas [...] aplicam-se às eletrônicas, e são agora aperfeiçoados, graças ao feedback quase instantâneo. As imperfeições persistem, como em qualquer sistema de avaliação, mas é possível mais eficiência, mais transparência e maior validação.
}

Em suma, o esforço rumo à qualidade das publicações deve ser um compromisso tanto de autores quanto de editores e avaliadores. Para tal, utilizam-se critérios que ajudam a verificar a qualidade aos periódicos científicos. Existem diversos modelos de avaliação, passíveis de adaptação com o fim de suprir necessidades específicas. Afora ajustamentos pontuais, Gonçalves, Ramos e Castro (2006), em consonância com Krzyzanowski e Ferreira (1998), distribuem os critérios em aspectos formais e de conteúdo. Os primeiros levam em conta formato e apresentação. Estão relacionados à qualidade da produção editorial. Dentre eles, os principais são: periodicidade e pontualidade; duração; normalização; trabalho editorial; difusão e indexação; endogenia; e, indicadores bibliométricos.

0 segundo agrupamento de parâmetros refere-se aos aspectos de conteúdo. Neste caso, considera-se a análise de pesquisadores atuantes da área, com experiência e conhecimento do contexto acadêmico-científico de determinada comunidade. Como envolve julgamento pessoal, o resultado da avaliação pode ter maior ou menor grau de subjetividade. Consideram-se os seguintes aspectos: caráter científico; revisão por pares; e, corpo editorial.

Em termos específicos, a depender da grande área e do suporte, há tópicos próprios, como os concernentes aos periódicos eletrônicos. Segundo Trzesniak (2006), ganha relevância a questão da preservação do conteúdo; a inclusão de metadados e a web semântica; o gerenciamento eletrônico do fluxo editorial, que permite maior ênfase na qualidade do processo produtivo, visto que desloca a preocupação das rotinas para o aperfeiçoamento das atividades do trabalho criativo. Soma-se a tudo isto, o desenvolvimento de sistemas e programas de revistas eletrônicas e a ideia de acesso aberto à informação.

Resumidamente, as principais vantagens do periódico científico eletrônico consistem em: maior agilidade na busca da informação e facilidade de acesso; mais rapidez na divulgação dos resultados das pesquisas; maior abertura de cientistas dispersos geograficamente para contribuição em grupos de pesquisa e de discussão; disseminação mais eficiente das informações, porquanto as informações são, agora, 
transmitidas segundo o perfil dos usuários; inovações na forma de apresentação das informações - aspecto que merece maior dedicação por parte das publicações que devem explorar maciçamente os recursos hipermidiáticos e hipertextuais -; facilidade de avaliação da recepção dos usuários via comentários críticos; velocidade de publicação; redução de custos operacionais e de manutenção de coleções; processos de armazenamento dispensáveis (TARGINO, 2001).

Em oposição, há desvantagens ou pontos de ponderação acerca das publicações eletrônicas. Questões de controle bibliográfico e preservação do conhecimento, bem como de treinamento e educação do usuário estão presentes. No entanto, em tempos de expansão incessante da internet e acesso aberto, problemas de ordem dos direitos autorais, mais do que nunca, estão em plena discussão.

Embora seja insensato afirmar que globalização e tecnologias sejam responsáveis pelos desvios éticos da produção científica, é válido reconhecer que facilitam a falsificação, adulteração ou apropriação da criação do outro, embora embuste e falcatrua existam no processo de criação e de editoração, mesmo no contexto da produção científica não eletrônica (TARGINO; GARCIA, 2008a). Por tudo isso, notifica-se a urgência no combate às diversas ocorrências de más condutas éticas e violação de direitos autorais, mormente, em se tratando de casos sequenciais e constantes de plágio.

Apesar das lacunas existentes, os artigos veiculados nessas publicações constituem arcabouço teórico de todo campo de conhecimento. Este estudo consolida o pensamento de Bufrem (2006). Para essa autora, analisado seu conteúdo numa perspectiva diacrônica, a revista científica oferece perspectivas para compreender a história da construção intelectual de áreas específicas do conhecimento, possibilitando profunda reflexão sobre conteúdos e métodos e, portanto, explorando tendências da literatura científica e influências teóricas.

\section{PROCEDIMENTOS METOLÓGICOS}

A natureza de uma investigação científica desperta sempre polêmica, uma vez que inexiste categorização universal ou consensual; condição que reforça a dificuldade que o pesquisador encontra para conceituar a tipologia de seu estudo. Cada vez mais, as pesquisas demandam conjunção de métodos e / ou técnicas. Assim, recorre-se a uma pesquisa bibliográfica e quali-quantitativa, haja vista que vai além da quantificação, para interpretar dados identificados e coletados ao longo da pesquisa.

Quanto aos fins propostos, o estudo caracteriza-se como descritivo, haja vista que a pesquisa descritiva se detém em esmiuçar as características de determinada população ou fenômeno ou estabelecimento de relações entre as variáveis. Dizendo de outra forma, a pesquisa em pauta coleta, registra e descreve com o intuito de revelar o status quo da pesquisa em $\mathrm{CI}$, nos dias atuais. A partir da realidade identificada e de maior conhecimento sobre sua configuração, é possível tecer reflexões aprofundadas e mais contundentes para contribuir com a área.

Quanto aos métodos, há dois tipos: o método técnico de investigação e o método lógico de investigação. Em relação ao método lógico, recorre-se ao método dedutivo, "que partindo das teorias e leis, na maioria das vezes, prediz a ocorrência dos fenômenos particulares [...]" (MARCONI; LAKATOS, 2000, p. 91). Em relação ao método técnico, a pesquisa adota o método estruturalista. Nele, os fatos são estudados per se e, ainda, em relação à conjuntura na qual se enquadram.

A pesquisa tem como universo os títulos de periódicos científicos eletrônicos nacionais da área de conhecimento da ciência da informação inseridos no Portal de Periódicos da Capes. Diante da impossibilidade de trabalhar com todas as revistas do Portal por sua quantidade elevada, em especial, em línguas estrangeiras, cerca de 400 títulos, em março de 2014, no campo da biblioteconomia e ciência da 
informação (COORDENAÇÃO DE APERFEIÇOAMENTO DE PESSOAL DE NÍVEL SUPERIOR, 2014b), recorre-se à amostra não probabilística intencional.

Na prática, há consenso de que na amostragem intencional, os erros de seleção e a incidência de equívocos se reduzem, haja vista que o próprio pesquisador restringe seu corpus mediante critérios lúcidos e coerentes com o objeto de estudo. No caso, além da limitação prévia da área, a amostra abrange os anos de 2003 a 2013, por seu nível de atualidade. Além do corte temporal, as unidades amostrais limitam-se àquelas que, em março de 2014, encontram-se conceituadas entre A1 e B2, exatamente pelo fato de tais notas corresponderem aos níveis mais elevados no quesito qualidade, ainda que sejam mutáveis, no mínimo, a cada ano. Para o estudo em evidência, a amostra não probabilística intencional totaliza 12 periódicos conforme constam no Apêndice e no Quadro 1.

Quadro 1: Informações Básicas Sobre os Títulos de Periódicos da Amostra

\begin{tabular}{|c|c|c|c|c|}
\hline ITEM & TÍTULO & QUALIS & EDITOR & $\begin{array}{l}\text { ANO DE } \\
\text { ORIGEM }\end{array}$ \\
\hline 01 & $\begin{array}{c}\text { Anais do Museu Paulista: História } \\
\text { e Cultura Material }\end{array}$ & A2 & Universidade de São Paulo (USP) & 1993 \\
\hline 02 & Ciência da Informação & $\mathrm{A} 2$ & $\begin{array}{c}\text { Instituto Brasileiro de } \\
\text { Informação em Ciência e } \\
\text { Tecnologia (IBICT) }\end{array}$ & 1997 \\
\hline 03 & $\begin{array}{l}\text { Datagramazero: Revista de } \\
\text { Informação }\end{array}$ & B1 & $\begin{array}{l}\text { Instituto de Adaptação e } \\
\text { Inserção na Sociedade da } \\
\text { Informação (IASI) }\end{array}$ & 2000 \\
\hline 04 & Em Questão & B1 & $\begin{array}{l}\text { Universidade Federal do Rio } \\
\text { Grande do Sul (UFRGS) }\end{array}$ & 2003 \\
\hline 05 & $\begin{array}{l}\text { Encontros Bibli: Revista Eletrônica } \\
\text { de Biblioteconomia e Ciência da } \\
\text { Informação }\end{array}$ & B1 & $\begin{array}{l}\text { Universidade Federal de Santa } \\
\text { Catarina (UFSC) }\end{array}$ & 1996 \\
\hline 06 & Intexto & B1 & $\begin{array}{c}\text { Universidade Federal do Rio } \\
\text { Grande do Sul (UFRGS) }\end{array}$ & 1997 \\
\hline 07 & Informação \& Informação & B2 & $\begin{array}{c}\text { Universidade Estadual de } \\
\text { Londrina (UEL) } \\
\end{array}$ & 1996 \\
\hline 08 & Informação \& Sociedade: Estudos & A1 & $\begin{array}{c}\text { Universidade Federal da Paraíba } \\
\text { (UFPB) }\end{array}$ & 1991 \\
\hline 09 & $\begin{array}{l}\text { Perspectivas em Ciência da } \\
\text { Informação }\end{array}$ & A1 & $\begin{array}{c}\text { Universidade Federal de Minas } \\
\text { Gerais (UFMG) }\end{array}$ & 1996 \\
\hline 10 & Revista ACB & B2 & $\begin{array}{c}\text { Associação Catarinense de } \\
\text { Bibliotecários (ACB) }\end{array}$ & 1996 \\
\hline 11 & $\begin{array}{l}\text { Revista Digital de Biblioteconomia } \\
\text { e Ciência da Informação (RDBCI) }\end{array}$ & B1 & $\begin{array}{c}\text { Universidade Estadual de } \\
\text { Campinas (Unicamp) }\end{array}$ & 2003 \\
\hline 12 & TransInformação & A1 & $\begin{array}{l}\text { Pontifícia Universidade Católica } \\
\text { (PUC - Campinas) }\end{array}$ & 2002 \\
\hline
\end{tabular}

Fonte

A amostra sintetiza-se quantitativamente: por estrato. São três títulos A1, dois $\mathrm{A} 2$, cinco $\mathrm{B} 1$ e dois B2; e, por região da instituição de origem do periódico, são cinco títulos da região Sul (ACB, UEL, UFRGS, UFSC), seis do Sudeste (IASI IBICT, UFMG, Unicamp, USP, PUC-Campinas) e um do Nordeste (UFPB). Respeitando-se os critérios estabelecidos pela Capes para a área de conhecimento ciência da informação, notificase na amostra a incidência de dez títulos "híbridos" de biblioteconomia e ciência da informação, um da comunicação e um da museologia. Ressalta-se que nenhum periódico da arquivologia se alinhou aos critérios, circunstância pela qual nenhum título desta área consta na amostra.

Quanto aos procedimentos, destacam-se dois aspectos: instrumentos e técnicas de coleta e análise de dados. Em relação aos procedimentos iniciais ou instrumentais, primeiros, diante do levantamento detalhado dos títulos / fascículos / artigos selecionados, em planilhas, as temáticas foram devidamente mapeadas, dentro do intervalo de tempo delimitado para o estudo.

Com relação às técnicas de coleta e análise, adotam-se a análise documental e a análise de conteúdo temática, descritas adiante. A análise documental, realizada a partir de fontes (contemporâneas ou retrospectos, escritas ou não), constitui o que 
Marconi e Lakatos (2008) denominam de fontes primárias. No caso em pauta, os artigos das revistas selecionadas. Tal procedimento se aplica a estudos de abordagem quantitativa e qualitativa em consonância à tipologia de pesquisa quali-quantitativa.

Se, a princípio a análise de conteúdo prioriza o enfoque quantitativo, cada vez mais, a AC permite abordagens tanto quantitativas quanto qualitativas. Bardin (1979, p. 42) a define:

[como] um conjunto de técnicas de análise de comunicações visando obter, por procedimentos sistemáticos e objetivos de descrição do conteúdo das mensagens, indicadores (quantitativos ou não) que permitem a inferência de conhecimentos relativos às condições de produção / recepção (variáveis inferidas) destas mensagens.

A análise de conteúdo presta-se tanto a fins exploratórios quanto à verificação, confirmando ou não hipóteses ou suposições preestabelecidas e comparações. Criamse categorias, resultantes do agrupamento de critérios assemelhados. 0 tema é sempre o conceito central, de modo a comportar um feixe de relações, que favorece descobrir núcleos de sentido que compõem um processo de comunicação cuja presença e / ou frequência atribuem significado ao objeto analisado. A forma de mensuração dos dados dá-se através da contagem da frequência das unidades de significação ou avaliação qualitativa. A presença de certos temas revela valores de referência e modelos de comportamento presentes no discurso (FRANCO, 2007).

Para operacionalizar a categorização e, por conseguinte, a análise mencionada, os dados coletados, a princípio, compõem quadros e / ou tabelas, levando em conta elementos: ano, número de artigos relacionados às temáticas, área relacionada e interdisciplinaridade, sob a ótica da abordagem quali-quantitativa. $\mathrm{Na}$ primeira etapa, os dados de cada título foram reunidos separadamente dos demais, ajudando a compor o perfil de cada publicação. Na etapa seguinte, os dados de todos os títulos se cruzam, possibilitando projetar resultados mais globais e mais próximos de conhecimento da realidade pretendida, com a ressalva de que tais procedimentos são de caráter interno. Isto é, não precisam chegar necessariamente ao público, a quem interessa os procedimentos adotados, mas, não, detalhes de intervenções que visam à concretização desses processos.

Para verificação e identificação mais precisa dos temas e / ou dos objetos de estudo de cada artigo, número a número, consideramos: título e subtítulo; resumo e / ou abstract; e palavras-chave e / ou keywords. São estes elementos indicativos centrais dos temas, com a ressalva de que há, sempre, a possibilidade de ir além, incluindo a leitura da introdução e de outras seções dos artigos, caso haja dificuldade para a devida identificação, até porque um mesmo artigo, como natural, pode apresentar compatibilidade com mais de uma categoria.

Priorizam-se os descritores utilizados pelos autores. Contudo, nenhuma categorização / classificação é consensual, haja vista que todo processo desta natureza envolve certo grau de subjetividade, o que torna inexequível suprir as expectativas de cada pesquisador ou profissional da informação. Por isto, recorre-se também à utilização de descritores adotados em vocabulários controlados com o objetivo mor de superar tendências à exaustividade excessiva na definição das categorias, além de se almejar a padronização dos termos.

A interpretação dos dados segue a categorização das temáticas abordadas nos artigos no período definido, relacionando-os com as possíveis contribuições para a área, comparando-se os principais temas de cada título. Ressalta-se a inclusão de artigos originais, artigos de revisão, comunicações, relatos de pesquisa e relatos de experiência, excluindo-se editoriais e recensões. Os artigos podem ser passíveis de inclusão em mais de uma categoria. Porém, face aos objetivos propostos, são eles enquadrados em sua categoria prevalecente. Quer dizer, mesmo quando um trabalho 
se situe em duas ou mais categorias, será inserido naquela com a qual apresente maior afinidade temática, considerando-se as demais como relações interdisciplinares. E diferentemente do que ocorre nas categorias em que se registra o artigo na classe prevalecente, quanto às áreas de conhecimento, enumeram-se quantas relações o artigo apresentar.

\section{IDENTIFICAÇÃO DAS TEMÁTICAS EM CIÊNCIA DA INFORMAÇÃO}

Os parâmetros adotados para o reconhecimento dos temas mais comuns em ciência da informação correspondem a uma conjunção de elementos - descritores adotados pelos autores, termos ou expressões constantes em vocabulários controlados - além de, em fase posterior, à análise documental e à análise de conteúdo temática. Como decorrência, a amostra assinala 48 categorias temáticas. Estas contemplam estudos de natureza teórico-prática e, portanto, abrangem fundamentos, conceitos e metodologias nas referidas categorias e subcategorias.

1. Administração

Administração de organizações públicas ou privadas voltadas à informação e / ou à melhoria em sua busca e em seu uso. Administração de empresas. Administração de recursos humanos. Administração pública;

2. Arquitetura da Informação

Conceitos e aplicação de arquitetura da informação em ambientes informacionais digitais;

3. Arquivos

Teorias e técnicas de arquivologia; administração, processos e atividades desenvolvidas em arquivos. Arquivos e arquivamento (documentos);

4. Arte e Arquitetura

Artes: coleções e colecionismo. Conservação e restauração de materiais. Escultura. Pintura. Retrato. Arquitetura em geral, tais como: fabril, hospitalar, industrial;

5. Autoria

Autoria (individual e coletiva). Direitos autorais. Licenças Creative Commons. Patentes. Propriedade intelectual;

6. Bibliotecas

Teorias e técnicas de biblioteconomia; administração, processos e atividades desenvolvidas em bibliotecas. Acervos bibliográficos. Arquitetura de bibliotecas. Avaliação e desenvolvimento de coleções. Cooperação bibliotecária. História das bibliotecas. Preservação dos acervos. Programas de atividades de bibliotecas;

7. Bibliotecas e Outras Unidades de Informação (Tipologia)

Diversos tipos de bibliotecas (comunitárias, escolares, especializadas, itinerantes, públicas e universitárias). Outros tipos de unidades de informação (diferentes de arquivos e museus), como brinquedotecas, centros de documentação e videotecas;

8. Bibliotecas Virtuais

Bibliotecas em ambiente digital. Repositórios digitais e / ou institucionais;

9. Busca e Uso da Informação

Comportamento informacional. Estratégias de busca e metacognitivas. Estudo de usuários. Necessidades de informação;

10. Ciberespaço

Computadores e civilização. Hipermídia. Hipertexto. Inclusão Digital. Inteligência coletiva. Interação homem-máquina. Virtualização e virtualidade;

11. Ciência da Informação

Conceitos e análises epistemológicas relacionados ao campo da ciência da informação. Antropologia da informação. Conceito de informação. Fluxo da informação. História da ciência da informação. História da documentação. Interdisciplinaridade. Pesquisa em ciência da informação. Teoria da ciência da informação. Teoria da informação; 
12. Ciência, Tecnologia e Inovação

Temas científicos universais a múltiplos campos de conhecimento. Agências de fomento. Ciência e tecnologia. Descoberta científica. Epistemologia. História da ciência. Inovação tecnológica. Metodologia científica. Ontologia (filosofia). Pesquisa científica. Pós-modernidade. Teoria do conhecimento;

13. Classificação

Categorias (filosofia). Classificação bibliográfica. Classificação de documentos (Conarq). Classificação do conhecimento. Classificação internacional de patentes (CIP). Folksonomia. Sistemas de classificação. Social bookmarks. Taxonomia;

14. Competências e Habilidades Informacionais

Desenvolvimento de competências e habilidades informacionais. Competência em informação. Educação de usuários. Letramento;

15. Comunicação e Divulgação Científica

Comunicação científica. Comunicação. Comunicologia. Interação social. Jornalismo. Jornalismo científico. Divulgação científica. Mídia. Imprensa. Publicidade. Rádio. Relações públicas. Televisão;

16. Comunidades Científicas e Redes Sociais

Colaboração científica. Comunidade científica. Comunidades de prática. Comunidades virtuais. Eventos científicos. Grupos de pesquisa. Pesquisadores. Redes sociais. Redes de relações sociais. Sociometria;

17. Conhecimento

Conhecimento científico. Conhecimento explícito. Conhecimento tácito. Teoria das representações sociais;

18. Documentos

Cartografia. Documentos eletrônicos. Normalização bibliográfica;

19. Ensino e Aprendizagem

Ambientes, ações, modalidades de ensino, formação e atuação de profissionais e legislação relativos à educação. Ambientes virtuais de aprendizagem. Aprendizagem colaborativa e organizacional. Bibliotecário educador. Educação. Educação a distância. Escolas e universidades. Ensino superior (graduação e pós-graduação). Sociedade da aprendizagem. Universidades;

20. Estudos Cognitivos e Comportamentais

Ciências cognitivas. Cognição. Data mining. Inteligências múltiplas. Motivação (psicologia). Redes cognitivas. Redes neurais (computação);

21. Estudos Métricos

Bibliometria. Cientometria. Estudo de citações. Indicadores bibliométricos. Indicadores em ciência e tecnologia. Infometria. Webometria;

22. Fontes de Informação

Bibliografia. Dissertações e teses. Enciclopédias e dicionários. Fotografia. Imagem. Prontuários de pacientes;

23. Geopolítica

Cooperação internacional. Diversidade cultural Geociências. Globalização. Identidade cultural. Indústria cultural. Mercosul. Planejamento governamental;

24. Gestão

Capital intelectual. Capital social Comunicação, controle, cultura e estrutura organizacional. Gestão. Gestão da informação. Gestão do conhecimento. Gestão da qualidade total Gestão documental. Gestão estratégica. Metodologia de sistemas flexíveis. Normas ISSO;

25. Gestão e Planejamento

Criação de conhecimento nas organizações. Inteligência competitiva e organizacional. Marketing. Tomada de decisão;

26. História

História econômica, natural, social e urbana;

27. Informação: Acesso e Disseminação 
Acessibilidade. Acesso à informação. Arquivos abertos (Open Archives). Direito à informação. Disseminação de informação. Disseminação seletiva da informação (DSI). Informação (agropecuária, ambiental, arquivística, artística, científica, corporativa, documentária, saúde, estatística, estética, estratégica, governamental, legislativa, negócios, pública, técnica, tecnológica e turística). Movimento de Acesso Aberto (Open Access). Tecnologias assistivas;

28. Internet

Internet na administração pública. Avaliação, classificação e estudo de usuários da World Wide Web (web). Jornalismo on-line;

29. Linguagem e Literatura

Linguagem e análise linguística. Gêneros: cinema; histórias em quadrinhos; música; narrativa e poética. Discurso. Estudos de recepção. Intertextualidade. Retórica. Teoria da enunciação;

30. Linguagens Documentárias e Terminologias

Linguagens documentárias. Ontologia. Terminologia. Tesauros e vocabulários controlados;

31. Linguagens e Protocolos (Informática)

Linguagens UML, XBRL, XML. Protocolo Z39.50;

32. Livro e Leitura

Biblioterapia. História do livro. Incentivo ao livro e à leitura, incluindo legislações específicas. Mercado editorial;

33. Mediação

Apropriação da informação. Mediação cultural e documental. Mediação da informação. Qualidade de informação. Transferência de informação;

34. Meio Ambiente e Sustentabilidade

Desenvolvimento sustentável e educação ambiental;

35. Memória

Memória coletiva, histórica e social;

36. Museus

Teorias e técnicas de museologia; administração, processos e atividades desenvolvidas em museus. Museu virtual. Preservação de material;

37. Organização, Representação e Descrição da Informação e Conhecimento

Catalogação. Catálogos de acesso público em linha (OPAC). Controle bibliográfico universal. Descrição da informação. Formato bibliográfico. Indexação. Mapa e modelagem conceitual. Metadados. Organização da informação e conhecimento. Representação da informação e conhecimento. Resource Description and Access (RDA) e Resource Description Framework (RDF);

38. Patrimônio

Educação patrimonial. Patrimônio arqueológico, cultural, documental e histórico;

39. Periódicos

Periódicos científicos (impressos e / ou eletrônicos): aquisição, avaliação, desenvolvimento de coleção, produção e uso. Avaliação por pares (peer review);

40. Políticas e Desenvolvimento

Cidadania. Democracia. Desenvolvimento humano e local. Economia política da comunicação. Estudos culturais. Inclusão e exclusão social. Medicina do trabalho. Políticas públicas: comunicação, informação, inovação, leitura e sociais. Regime de informação. Responsabilidade social. Saúde pública. Segurança pública. Sociedade da informação e do conhecimento. Trabalho. Trabalho voluntário;

41. Preservação da Informação

Digitalização. Preservação digital. Preservação documental;

42. Produção e Produtividade Científica

Fator de impacto. Institute for Scientific Information (ISI). Lei de Lotka. Produção científica e produtividade dos autores;

43. Produtos e Serviços de Informação 
Ação cultural. Marketing de serviços. Serviços de informação;

44. Profissional da Informação

Atuação e ética profissional. Profissionais da informação: arquitetos de informação, arquivistas, jornalistas e profissionais de bibliotecas (bibliotecários e auxiliares de bibliotecas). Profissionais da informação e perfil. Competências e formação. Mercado de trabalho. Entidades de classe;

45. Recuperação de Informação

Sistemas de recuperação de informação;

46. Signos e Significado

Iconografia. Imagem técnica. Semântica. Semiótica. Web semântica;

47. Sistemas de Informação

Agentes inteligentes (softwares). Bancos e bases de dados. Interoperação. Sistemas de informação gerencial. Sistemas imageadores na medicina. Visualização de informação (ferramentas de software);

48. Tecnologias da Informação

Convergência tecnológica. Dispositivos móveis. Mídias digitais. Tecnologias de informação e de comunicação. Tecnologias de informação e do conhecimento. Telecomunicações.

\section{NÚMERO DE ARTIGOS RELACIONADOS ÀS CATEGORIAS}

Diante da identificação das categorias, é o momento de verificar quais as mais debatidas no campo significativamente interdisciplinar da ciência da informação. Isto pressupõe quantificar o total de artigos relacionados a cada uma delas (Tabela 1). De posse dos dados listados, destacam-se as categorias com os maiores índices de produção. O primeiro lugar é conquistado por Gestão (191 artigos), haja vista a relevância que a gestão de conteúdos informacionais alcança, no âmbito organizacional, em nível crescente. Quer dizer, os resultados obtidos ratificam o crescimento dos estudos sobre gestão nos periódicos científicos. A categoria enfocada é ampla e reúne temas voltados à informação nas organizações e associações, sejam empresariais ou institucionais.

Ainda em conformidade com a Tabela 1, a categoria Comunicação e Divulgação Científica enfatiza a força da circulação dos conhecimentos científicos tanto no âmbito da comunidade científica quanto em nível de coletividades, favorecendo o aprimoramento do próprio campo de conhecimento. A classe discutida reúne, além de conteúdos propriamente ditos sobre comunicação científica, artigos do campo da comunicação, como jornalismo e publicidade. Confirma-se o valor desses estudos para a CI: basta evocar o valor da comunicação científica e o papel da imprensa para a expansão do campo comunicacional.

A seguir, as classes Estudos Métricos e Profissional da Informação estão praticamente empatadas. Sobre as análises métricas, estas propiciam compreender o incremento do campo, através da aplicação de técnicas de mensuração que estipulam indicadores que permitem caracterizar um perfil científico - razão pela qual os estudos da categoria são benéficos a múltiplas áreas de conhecimento. No que se refere aos profissionais da informação, verifica-se, sobremaneira, enfoque sobre bibliotecários e jornalistas. No âmbito da biblioteconomia, prevalecem textos acerca de competência e formação profissional. Por sua vez, na comunicação, predominam estudos acerca da atuação profissional. A Tabela 1 sintetiza os dados quantitativos referentes a cada categoria. 
Tabela 1: Categorias Temáticas

\begin{tabular}{|c|c|c|}
\hline CATEGORIAS & QUANTIDADE & $\%$ \\
\hline Administração & 7 & $0,23 \%$ \\
\hline Arquitetura da Informação & 19 & $0,59 \%$ \\
\hline Arquivos & 45 & $1,40 \%$ \\
\hline Arte e Arquitetura & 48 & $1,49 \%$ \\
\hline Autoria & 30 & $0,93 \%$ \\
\hline Bibliotecas & 78 & $2,42 \%$ \\
\hline Bibliotecas e Outras Unidades de Informação (Tipologia) & 52 & $1,61 \%$ \\
\hline Bibliotecas Virtuais & 66 & $2,05 \%$ \\
\hline Busca e Uso da Informação & 101 & $3,13 \%$ \\
\hline Ciberespaço & 82 & $2,55 \%$ \\
\hline Ciência da Informação & 136 & $4,22 \%$ \\
\hline Ciência, Tecnologia e Inovação & 71 & $2,20 \%$ \\
\hline Classificação & 56 & $1,74 \%$ \\
\hline Competências e Habilidades Informacionais & 52 & $1,61 \%$ \\
\hline Comunicação e Divulgação Científica & 172 & $5,34 \%$ \\
\hline Comunidades Científicas e Redes Sociais & 72 & $2,23 \%$ \\
\hline Conhecimento & 18 & $0,56 \%$ \\
\hline Documentos & 27 & $0,84 \%$ \\
\hline Ensino e Aprendizagem & 77 & $2,39 \%$ \\
\hline Estudos Cognitivos e Comportamentais & 11 & $0,34 \%$ \\
\hline Estudos Métricos & 156 & $4,84 \%$ \\
\hline Fontes de Informação & 43 & $1,33 \%$ \\
\hline Geopolítica & 20 & $0,62 \%$ \\
\hline Gestão & 191 & $5,93 \%$ \\
\hline Gestão e Planejamento & 86 & $2,67 \%$ \\
\hline História & 29 & $0,90 \%$ \\
\hline Informação: Acesso e Disseminação & 115 & $3,57 \%$ \\
\hline Internet & 97 & $3,01 \%$ \\
\hline Linguagem e Literatura & 94 & $2,92 \%$ \\
\hline Linguagens Documentárias e Terminologias & 72 & $2,23 \%$ \\
\hline Linguagens e Protocolos (Informática) & 10 & $0,31 \%$ \\
\hline Livro e Leitura & 72 & $2,23 \%$ \\
\hline Mediação & 42 & $1,30 \%$ \\
\hline Meio Ambiente e Sustentabilidade & 7 & $0,23 \%$ \\
\hline Memória & 39 & $1,21 \%$ \\
\hline Museus & 60 & $1,86 \%$ \\
\hline Organização, Representação e Descrição da Informação e Conhecimento & 138 & $4,28 \%$ \\
\hline Patrimônio & 22 & $0,68 \%$ \\
\hline Periódicos & 77 & $2,39 \%$ \\
\hline Políticas e Desenvolvimento & 133 & $4,13 \%$ \\
\hline Preservação da Informação & 38 & $1,18 \%$ \\
\hline Produção e Produtividade Científica & 67 & $2,08 \%$ \\
\hline Produtos e Serviços de Informação & 48 & $1,49 \%$ \\
\hline Profissional da Informação & 154 & $4,78 \%$ \\
\hline Recuperação de Informação & 27 & $0,84 \%$ \\
\hline Signos e Significado & 38 & $1,18 \%$ \\
\hline Sistemas de Informação & 70 & $2,17 \%$ \\
\hline Tecnologias da Informação & 57 & $1,77 \%$ \\
\hline TOTAL & 3.222 & $100,00 \%$ \\
\hline
\end{tabular}

Fonte

Ainda sobre as categorias agrupadas na Tabela 1, destacam-se Organização, Representação e Descrição da Informação e Conhecimento; e, ainda, Ciência da Informação. Em termos genéricos e "de olho" na mencionada Tabela, percebe-se ser comum identificar pesquisas no âmbito da organização e da representação da informação entre as mais frequentes, devido à especialidade do campo em produzir trabalhos voltados ao arranjo e à ordenação da informação tangível, ou, em alusão ao pensamento de Buckland (1991), a informação como "coisa" (information-as-thing), ainda que se registrem outras tendências de pesquisa nessa esfera, como o enfoque cognitivo. Sucessivamente, os estudos pertencentes à categoria Ciência da Informação dedicam-se a examinar o campo para tratar de seus aspectos filosóficos e refletir 
sobre a investigação científica na área, inclusive no que diz respeito à interdisciplinaridade.

Com relação aos índices mais baixos de produção, Administração; e Meio Ambiente e Sustentabilidade coincidem com o menor número: sete. Paradoxalmente, no âmbito da Administração, registram-se os menores números de artigos publicados - ao contrário dos temas específicos em Gestão. Acredita-se que esta disciplina desponta mais significativamente como área de conhecimento interdisciplinar (em destaque mais adiante na Tabela 2) do que como categoria, porque a CI se interessa, particularmente, por questões que envolvem o gerenciamento de fluxos e / ou unidades de informação em detrimento de aspectos mais amplos como administração pública ou de empresas. Concomitantemente, ainda que em relação à educação e informação ambiental, o enfoque específico aos tópicos ambientais pode ser considerado ínfimo.

Também com índices pouco significativos estão Estudos Cognitivos e Comportamentais; e Linguagens e Protocolos (Informática). Notifica-se o interesse de pesquisadores da CI pelas ciências cognitivas, especialmente aqueles que se dedicam a pesquisar sobre organização e representação da informação. Entretanto, a produção científica não repercute expressivamente estudos nesta categoria. Situação similar (baixo número de artigos) ocorre no âmbito das linguagens da informática; embora a ciência da computação apareça com maior relevância comparada às ciências cognitivas.

Sobre a categoria Conhecimento, vale ressaltar que a maior parte dos artigos a este respeito associa-se à gestão do conhecimento. Tal fato justifica a limitada quantidade de trabalhos neste setor. Embora Arquitetura da Informação apresente baixa produção, configura-se como categoria em ascendência. Isto porque, na condição de disciplina, apresenta frequência intermediária nas relações interdisciplinares, tendo em conta a aplicação de seus conceitos teóricos nos artigos da área de ciência da informação.

Continuando esta exposição, salienta-se que estudos sobre Geopolítica constam em número diminuto e ainda assim com acentuada dispersão temática na categoria. Registra-se, ainda, a pouca frequência de estudos sobre Patrimônio. Segundo a Associação Nacional de Pesquisa e Pós-Graduação em Ciência da Informação (2015), o Grupo de Trabalho 9 - Museu, Patrimônio e Informação advém do grupo Debates em Museologia e Patrimônio, cujo interesse é o entrelace Museologia e Ciência da Informação; bem como, seu ano oficial de criação é 2008. Conclui-se que este cenário tem relação com a baixa produtividade da categoria, haja vista o domínio e o tempo de existência do grupo.

Por fim, chama também atenção os percentuais baixos para Documentos; e Recuperação de Informação. Em relação ao primeiro, a provável causa é o nível de especificidade; sobre o segundo, acredita-se que isto ocorra em virtude de tais estudos se concentrarem mais em examinar estratégias e mecanismos de busca ou sistemas de informação (temáticas agrupadas em Busca e Uso da Informação e Sistemas de Informação) em detrimento dos sistemas de recuperação de informação, enfatizados na categoria abordada.

\section{7 ÁREAS DE CONHECIMENTO INTERDISCIPLINAR}

Frente ao objetivo deste artigo, investigam-se áreas de conhecimento que manifestem relação interdisciplinar com a ciência da informação (Tabela 2). 
Tabela 2: Relações Interdisciplinares

\begin{tabular}{|c|c|c|}
\hline DISCIPLINAS & QUANTIDADE & $\%$ \\
\hline Administração & 233 & $9,51 \%$ \\
\hline Agricultura & 2 & $0,08 \%$ \\
\hline Arqueologia & 5 & $0,20 \%$ \\
\hline Arquitetura da Informação & 44 & $1,80 \%$ \\
\hline Arquitetura e Urbanismo & 21 & $0,86 \%$ \\
\hline Arquivologia & 110 & $4,49 \%$ \\
\hline Artes & 101 & $4,12 \%$ \\
\hline Biblioteconomia & 665 & $27,14 \%$ \\
\hline Ciência da Computação & 117 & $4,78 \%$ \\
\hline Ciências Agrárias & 1 & $0,04 \%$ \\
\hline Ciências Biológicas & 13 & $0,53 \%$ \\
\hline Ciências Cognitivas & 44 & $1,80 \%$ \\
\hline Ciências Contábeis & 2 & $0,08 \%$ \\
\hline Ciências da Saúde & 38 & $1,55 \%$ \\
\hline Ciências Humanas & 9 & $0,37 \%$ \\
\hline Ciências Naturais & 2 & $0,08 \%$ \\
\hline Ciências Sociais & 75 & $3,06 \%$ \\
\hline Comunicação & 334 & $13,63 \%$ \\
\hline Design & 1 & $0,04 \%$ \\
\hline Direito & 48 & $1,96 \%$ \\
\hline Documentação & 17 & $0,69 \%$ \\
\hline Ecologia & 16 & $0,66 \%$ \\
\hline Economia & 14 & $0,58 \%$ \\
\hline Educação & 74 & $3,02 \%$ \\
\hline Educação Física & 4 & $0,16 \%$ \\
\hline Engenharia de Software & 18 & $0,73 \%$ \\
\hline Ergonomia & 4 & $0,16 \%$ \\
\hline Estatística & 15 & $0,62 \%$ \\
\hline Filosofia & 59 & $2,41 \%$ \\
\hline Física & 1 & $0,04 \%$ \\
\hline Geociências & 1 & $0,04 \%$ \\
\hline Geografia & 23 & $0,94 \%$ \\
\hline Geologia & 2 & $0,08 \%$ \\
\hline História & 67 & $2,73 \%$ \\
\hline Letras & 2 & $0,08 \%$ \\
\hline Linguística & 58 & $2,37 \%$ \\
\hline Literatura & 22 & $0,90 \%$ \\
\hline Matemática & 4 & $0,16 \%$ \\
\hline Museologia & 75 & $3,06 \%$ \\
\hline Nanotecnologia & 1 & $0,04 \%$ \\
\hline Pedagogia & 4 & $0,16 \%$ \\
\hline Psicologia & 13 & $0,53 \%$ \\
\hline Semântica & 20 & $0,82 \%$ \\
\hline Semiótica & 60 & $2,45 \%$ \\
\hline Serviço Social & 1 & $0,04 \%$ \\
\hline Turismo & 10 & $0,41 \%$ \\
\hline TOTAL & 2.450 & $100,00 \%$ \\
\hline
\end{tabular}

Fonte

No que diz respeito às relações interdisciplinares, cinco áreas se destacam por apresentarem os maiores índices de frequência na amostra. Nesse sentido, destacam-se os grupos Biblioteconomia, seguido por Comunicação, Administração, Ciência da Computação e Arquivologia.

0 fato de a categoria Biblioteconomia aparecer com o índice de maior relação interdisciplinar se explica na história tanto da ciência da informação quanto das próprias publicações científicas do campo estudado - circunstância realçada neste trabalho para justificar a investigação nos periódicos de biblioteconomia e CI. É o que ocorre, por exemplo, com a Revista ACB, cuja ênfase consiste nos trabalhos de biblioteconomia, em especial, no que tange à formação e à atuação de profissionais da informação (Tabela 2). 
A comunicação também se destaca na amostra, sobretudo, em títulos, como Em Questão e Intexto, em que prevalecem artigos do referido campo de conhecimento. De forma relevante, os trabalhos dessa área possuem relação também com os campos de linguística e semiótica, sobremaneira quando tratam de estudos sobre discurso. Por sua vez, a relação com a área de administração se evidencia em papers sobre gestão, como: gestão de unidades de informação; gestão da informação e do conhecimento; e, inteligência competitiva.

A afinidade com a ciência da computação predomina em trabalhos do âmbito da organização da informação; cujos temas englobam descrição, representação, recuperação e sistemas de informação. A arquivologia acentua sua conexão com a CI por abranger análises acerca de temas como descrição e gestão da informação arquivística.

Vale ressaltar que dentre as cinco áreas com maiores índices de interdisciplinaridade, constam duas disciplinas das chamadas "3 Marias" (SMIT, 1993): Biblioteconomia (a autora agrega aqui a Documentação) e Arquivologia. A terceira é a Museologia, presente na amostra - especialmente em artigos da revista Anais do Museu Paulista - porém com menor incidência geral nos estudos.

Quanto aos menores percentuais, há empate entre áreas como: Ciências Agrárias, Serviço Social, Nanotecnologia, Geociências, Geografia, Design e Física, com um único artigo. Também apresentam baixa incidência: Agricultura, Ciências Contábeis, Ciências Naturais, Geologia e Letras (dois); Arqueologia (cinco); Educação Física, Ergonomia, Matemática e Pedagogia (quatro); Ciências Humanas (nove); Turismo (10); e, por fim, Ciências Biológicas e Psicologia, com 13 menções.

Com base em enunciados da área de estudo enfocada, o panorama ora identificado não causa estranheza, uma vez que indicam que as áreas de conhecimento mencionadas não se estabilizam em situação de proximidade com o campo da CI, visto que:

1. Não fazem parte da variedade de profissionais envolvidos no advento da $\mathrm{CI}$, tais como: bibliotecários, cientistas da computação, engenheiros, linguistas, cientistas, dentre outros (SARACEVIC, 1996);

2. Não se enquadram nas três categorias do campo da CI: recuperação de informação, comunicação da informação e estudos da cognição (FREIRE; FREIRE, 2009);

3. Não estão entre as sete tendências da CI: biblioteconomia; arquivologia e museologia; ciência da computação; ciências cognitivas; comunicação; contexto das ciências sociais e humanas; administração (gestão da informação) e economia; e, por fim, as ciências da saúde (SILVA, 2013).

\section{SÍNTESE DOS RESULTADOS: SEMELHANÇAS E DIFERENÇAS TEMÁTICAS NO ÂMBITO DA INTERDICIPLINARIDADE}

Ainda frente ao objetivo deste estudo, vale destacar que a identificação das categorias e das áreas de conhecimento com as quais a CI se relaciona, evidencia sua natureza interdisciplinar e colabora para o desenvolvimento do campo. Destarte, as categorias apresentam, por vezes, semelhanças entre si e com as áreas de conhecimento identificadas.

No âmbito das semelhanças, dispõem-se tais inferências:

1. Administração; Gestão; Gestão e Planejamento, além de serem categorias que se inter-relacionam, conservam eixo comum na Administração;

2. Bibliotecas; Bibliotecas e Outras Unidades de Informação (Tipologia); e Bibliotecas Virtuais, possuem eixo comum em Biblioteconomia;

3. Busca e Uso da Informação; Classificação; Linguagens Documentárias e Terminologias; Linguagens e Protocolos (Informática); Organização, Representação e 
Descrição da Informação e Conhecimento; Preservação da Informação; Recuperação de Informação; Sistemas de Informação; e, Tecnologias da Informação, encontram em Biblioteconomia, Ciência da Computação e Ciências Cognitivas as principais áreas de confluência;

4. Ciberespaço e internet convergem especialmente para os campos da Ciência da Computação e das Ciências Sociais;

5. Competências e Habilidades Informacionais; Mediação; Produtos e Serviços de Informação; e, Profissional da Informação; amiúde, vinculam-se às áreas de Biblioteconomia, Educação e Pedagogia;

6. As categorias Comunicação e Divulgação Científica; e, Comunidades Cientificas e Redes Sociais associam-se à Comunicação;

7. Documentos; Fontes de Informação; e, Periódicos relacionam-se com a Biblioteconomia, além da Arquivologia e História, embora se configurem, também, como classes de interesse de campos diversos;

8. Ensino e Aprendizagem; Linguagem e Literatura; e, Livro e Leitura vinculam-se especialmente com a Educação, Linguística e Literatura, ainda que a Biblioteconomia mencione artigos sobre o bibliotecário educador;

9. Estudos Métricos; e, Produção e Produtividade Científica são categorias complementares, assim como Políticas e Desenvolvimento; Informação: Acesso e Disseminação apresentam compatibilidade. Dada à sua amplitude, estabelecem relação com áreas de conhecimento diversas.

No âmbito das diferenças, infere-se:

1. As categorias de domínio mais estrito - exceto Ciência da Informação, cuja produção é consistente; bem como, Ciência, Tecnologia e Inovação com moderada regularidade - como Arquitetura da Informação; Arquivos; Arte e Arquitetura; Autoria; Conhecimento; e, por fim, Meio Ambiente e Sustentabilidade figuram entre aquelas com índices mais ínfimos de produção científica, no caso de periódicos eletrônicos. Porém, congregam temáticas importantes não contempladas nos artigos de periódicos e que podem enriquecer os estudos da área, sejam aquelas que apresentam potencial de ascensão como Arquitetura da Informação e Autoria, ou ainda as que se destinam a temas em voga, como Meio Ambiente e Sustentabilidade. Outro ponto a se mencionar é o fato de estudos a respeito de arquivos e museus se encontrarem neste grupo, haja vista que suas disciplinas mostram moderada frequência nas relações interdisciplinares;

2. Estudos Cognitivos e Comportamentais; e, Signos e Significado são categorias que se concatenam em torno das Ciências Cognitivas. Contudo, apresentam número modesto de relações interdisciplinares, apesar de se configurar como tendência nos estudos em CI;

3. Geopolítica encontra-se também entre as categorias com menor número de artigos. Embora, mantendo correlação com Políticas e Desenvolvimento, a CI, atualmente, dedica-se mais às políticas públicas de informação do que aos temas globalização e identidade cultural, por exemplo;

4. História; Memória; Museus; e, Patrimônio apresentam compatibilidade temática entre si; contudo, exceto pela primeira, as demais categorias apresentam produção restrita. Deste modo, ressalta-se a relevância de tais estudos para o campo da CI e notificam-se suas perspectivas futuras;

Finalizando, recomenda-se que pesquisadores da área voltem sua atenção aos temas em ascensão, ainda pouco explorados no âmbito da CI, haja vista as perspectivas de crescimento e de contribuição ao campo. Todas as temáticas são relevantes, porém algumas carecem de maior empenho, uma vez que os estudos estão em fase de amadurecimento. 


\section{CONSIDERAÇÕES FINAIS}

Ratifica-se que a ciência atual favorece o diálogo entre as disciplinas, sem estimular o enclausuramento, haja vista que percebe como profícuo o compartilhamento de conhecimentos entre os diferentes campos, e, por conseguinte, entre as variadas especializações e disciplinas. Assim, ampliam-se não somente as relações interdisciplinares, mas, ainda, as temáticas e subtemáticas exploradas nos campos do saber científico. Como inevitável, tal conjuntura se reflete na produção científica, em especial, nos periódicos, graças à visibilidade dessa modalidade de publicação, com ênfase para os títulos eletrônicos.

Diante do objetivo deste estudo, as inferências advindas dos dados coletados e analisados evidenciam que a amostra é composta por 3.222 artigos, os quais se distribuem entre 48 categorias temáticas com subitens, o que confirma a expansão do campo da CI. A literatura confirma o incremento dos cursos de pós-graduação na área como elemento interveniente para a edição dos primeiros periódicos brasileiros de biblioteconomia e CI mais consolidados, contexto que influencia diretamente a comunicação científica, sobretudo, quando favorecida pelo meio eletrônico.

Além disso, o número de artigos referentes às temáticas revela visível discrepância entre as categorias. Enquanto Gestão; Comunicação e Divulgação Científica; Estudos Métricos; Profissional da Informação; Organização, Representação e Descrição da Informação e Conhecimento; e Ciência da Informação são seis classes amplamente exploradas nos estudos, em contraposição, Administração; Meio Ambiente e Sustentabilidade; Estudos Cognitivos e Comportamentais; Linguagens e Protocolos (Informática); Conhecimento; Arquitetura da Informação; Geopolítica; Patrimônio; Documentos; e Recuperação de Informação aparecem em número diminuto na amostra, considerando-se o período enfocado. Exemplificando: enquanto a categoria Gestão abrange 191 artigos, apenas sete pertencem a Meio Ambiente e Sustentabilidade.

Em sequência, quantificam-se na amostra, 2.450 relações interdisciplinares, dentre as quais a CI ocupa destaque estabelecendo intrínsecas relações com as categorias: Biblioteconomia; Comunicação; Administração; Ciência da Computação e Arquivologia. Em contrapartida, algumas de tais relações não se encontram igualmente consolidadas, tais como: Ciências Agrárias; Serviço Social; Nanotecnologia; Geociências; Geografia; Design; Física; Agricultura, Ciências Contábeis, Ciências Naturais, Geologia; Letras; Arqueologia; Educação Física; Ergonomia; Matemática; Pedagogia; Ciências Humanas; Turismo; Ciências Biológicas e Psicologia.

Devido à natureza interdisciplinar da CI, as categorias e disciplinas nas quais o campo mantém relação convergem entre si. Contudo, como inevitável, aquelas com os menores índices de artigos publicados, embora relevantes, não são amplamente examinadas como as que estão em evidência no período. Ressalta-se a importância em incrementar tais estudos a fim de se evitar negligenciar temas importantes no desenvolvimento desse campo científico.

\section{REFERÊNCIAS}

ANDRADE, M. E. A.; OLIVEIRA, M. A ciência da informação no Brasil. In: OLIVEIRA, M. (Org.). Ciência da informação e biblioteconomia: novos conteúdos e espaços de atuação. Belo Horizonte: UFMG, 2005. p. 45-56.

ARAÚJO, A. C.; BUFREM, L. S. Informação para negócios: aspectos da literatura científica nacional em revistas da área de ciência da informação. Ciência da

informação, Brasília, v. 37, n. 1, p. 7-17, jan./abr. 2008. 
ASSOCIAÇÃO NACIONAL DE PESQUISA E PÓS-GRADUAÇÃO EM CIÊNCIA DA IFNORMAÇÃO. GT 9: museu, patrimônio e informação. 2015b. Disponível em:

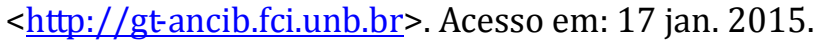

BARDIN, L. Análise de conteúdo. Lisboa: Ed. 70, 1979.

BOMFÁ, C. R.; CASTRO, J. E. Desenvolvimento de revistas científicas em mídia digital: o caso da Revista Produção Online. Ciência da Informação, Brasília, v.33, n.2, p.39-48, maio/ago. 2004.

BUCKLAND, M. K. Information and Information Systems. New York: [s.n.], 1991.

BUFREM, L. S. Revistas científicas: saberes no campo da ciência da informação. In: POBLACION, D. A.; WITTER, G. P.; SILVA, J. F. M. (Org.). Comunicação \& produção científica: contexto, indicadores e avaliação. São Paulo: Angellara, 2006. Cap. 7, p. 191-214.

COORDENAÇÃO DE APERFEIÇOAMENTO DE PESSOAL DE NÍVEL SUPERIOR. Tabelas das áreas do conhecimento. 2012. Disponível em:

$<$ http://www.capes.gov.br/images/stories/download/avaliacao/TabelaAreasConheci mento_072012.pdf>. Acesso em: 13 mar. 2014.

Qualis Periódicos. Disponível em: <

http://www.capes.gov.br/avaliacao/qualis>. Acesso em: 3 mar. 2014a.

. Portal de Periódicos. Buscar Periódico. Disponível em:

<http://www.periodicos.capes.gov.br>. Acesso em: 3 mar. 2014b.

CORREIA, A. E. G. C.; ALVARENGA, L.; GARCIA, J. C. R. Produção científica: reflexos da avaliação nos programas de pós-graduação em física. Em Questão, Porto Alegre, v. 18, ed. esp., p. 231-247, dez. 2012.

FRANCO, M. L. P. B. Análise do conteúdo. 2. ed. Brasília: Liber Livro, 2007. Série pesquisa. v. 6.

FREIRE, G.; FREIRE, I. Introdução à ciência da informação. João Pessoa: UFPB, 2009.

GONÇALVES, A.; RAMOS, L. M. S. V. C.; CASTRO, R. C. F. Revistas científicas: características, funções e critérios de qualidade. In: POBLACION, D. A.; WITTER, G. P.; SILVA, J. F. M. (Org.). Comunicação \& produção científica: contexto, indicadores e avaliação. São Paulo: Angellara, 2006. Cap. 6, p. 163-190.

KRZYZANOWSKI, R. F.; FERREIRA, M. C. G. Avaliação de periódicos científicos e técnicos brasileiros. Ciência da Informação, Brasília, v. 27, n. 2, p. 165-175, maio/ago. 1998.

LEITE, F. T. Metodologia científica: iniciação à pesquisa científica, métodos e técnicas de pesquisa, metodologia da pesquisa e do trabalho científico (monografias, dissertações, teses e livros). Fortaleza: Universidade de Fortaleza, 2004.

MARCONI, M. A.; LAKATOS, E. M. Metodologia científica. 3. ed. São Paulo; Atlas, 2000. 
. Técnicas de Pesquisa. 7. ed. São Paulo: Atlas, 2008.

MIRANDA, A. Estudos avançados em arquivologia, biblioteconomia e ciência da informação. v. 2, 2002. Apresentação da obra. Disponível em:

$<$ http://www.antoniomiranda.com.br/ciencia informacao/apresenta miranda georg ete.pdf.>. Acesso em: 20 jun. 2014.

SARACEVIC, T. Ciência da informação: origem, evolução e relações. Perspectivas em Ciência da Informação, Belo Horizonte, v. 1, n. 1, p. 41-62, jan./jun. 1996.

SILVA, A. K. A.; CORREIA, A. E. G. C.; LIMA, I. F. O conhecimento e as tecnologias da sociedade da informação. Revista Interamericana de Bibliotecología, Medellín, v. 33, n. 1, ene. / jun. 2010.

SILVA, J. L. C. Das concepções disciplinares na ciência da informação e / ou de suas configurações epistemológicas: o desiderato percepcionado da interdisciplinaridade. Investigación Bibliotecológica, México, v. 27, n. 59, p. 67-92, ene. / abr. 2013.

SMIT, J. W. 0 documento audiovisual ou a proximidade entre as 3 Marias. Revista Brasileira de Biblioteconomia e Documentação, São Paulo, v. 26, n. 1/2, p. 81-85, 1993.

TARGINO, M. G. Comunicação científica na sociedade tecnológica: periódicos eletrônicos em discussão. Comunicação e sociedade, v. 3, p. 93-112, 2001.

TARGINO, M. G.; GARCIA, J. C. R. Responsabilidade ética e social na produção de periódicos científicos. Belo Horizonte, Perspectivas em Ciência da informação, v.13, n.1, p.33-54, jan./abr. 2008a.

. 0 e editor e a revista científica: entre "o feijão e o sonho". In: FERREIRA, S. M. S. P.; TARGINO, M. G. (Org.). Mais sobre revistas científicas: em foco a gestão. São Paulo: Editora Senac São Paulo, Cengage Learning, 2008b. p. 41-72.

TRZESNIAK, P. As dimensões da qualidade dos periódicos científicos e sua presença em um instrumento da área de educação. Revista Brasileira de Educação, v. 11, n. 32, p. 346-377, maio/ago. 2006.

\section{APÊNDICE \\ Sobre os títulos de periódicos da amostra}

Anais do Museu Paulista: História e Cultura Material, http://www.scielo.br/revistas/anaismp

Anais do Museu Paulista é uma publicação semestral da Universidade de São Paulo, cujo primeiro número data de 1922. A partir de 1993 passa a circular em nova série, com o subtítulo História e Cultura Material. Discute temas polêmicos e balanços historiográficos, especialmente da história dos museus. Apresenta contribuições de historiadores, antropólogos, sociólogos, arquitetos, geógrafos, etnólogos, arqueólogos, museólogos e documentalistas, entre outros profissionais.

Ciência da Informação, http://www.scielo.br/revistas/ci

Ciência da Informação é uma publicação quadrimestral do IBICT, denominado à época do primeiro número, em 1972, e até 1975, de Instituto Brasileiro de Bibliografia e Documentação (IBBD). Com atuação marcante no campo da CI, publica trabalhos acerca do campo de 
conhecimento citado e áreas correlatas. Destacam-se as temáticas dos setores de informação, ciência e tecnologia.

Datagramazero: Revista de Informação,

http://www.dgz.org.br

Datagramazero é uma publicação bimestral que se diferencia por ser uma revista de propriedade privada. Com vistas ao novo padrão de escrita e leitura na $w e b$, seu primeiro número é de 1999, com o objetivo de reunir textos, divulgar e promover perspectivas críticas fundamentadas nas áreas interdisciplinares da CI, como os que envolvem informação e assuntos como: sociedade, políticas públicas, filosofia e comunicação.

Em Questão,

http://seer.ufrgs.br/emquestao

Em Questão é uma revista semestral publicada pela Faculdade de Biblioteconomia e Comunicação da Universidade Federal do Rio Grande do Sul, dirigida a pesquisadores, professores, profissionais e estudantes das áreas de informação e comunicação. Seu primeiro número é de 2003, quando substitui a Revista de Biblioteconomia \& Comunicação, período de 1986-2000. Seu principal objetivo é divulgar estudos e resultados de pesquisas nos campos da informação e comunicação e áreas afins.

Encontros Bibli: Revista Eletrônica de Biblioteconomia e Ciência da Informação, https://periodicos.ufsc.br/index.php/eb/index

Encontros Bibli é um periódico publicado pela Universidade Federal de Santa Catarina de periodicidade quadrimestral, cujo primeiro número é de 1996. Objetiva contribuir para a disseminação e promoção de novos conhecimentos em biblioteconomia, CI e áreas correlatas.

Intexto,

http://www.seer.ufrgs.br/intexto/index

Intexto é uma revista semestral do Programa de Pós-Graduação em Comunicação e Informação da Universidade Federal do Rio Grande do Sul. Fundada em 1997, reúne trabalhos sobre temáticas pertinentes à comunicação, informação e áreas afins.

Informação \& Informação, http://www.uel.br/revistas/informacao

Informação \& Informação é uma publicação quadrimestral do Departamento de Ciência da Informação da Universidade Estadual de Londrina. Lançada em 1996, a partir de 2003 passa a adotar exclusivamente o formato eletrônico. Apresenta artigos inéditos em CI, arquivologia, biblioteconomia e áreas interdisciplinares.

Informação \& Sociedade: Estudos,

http://www.ies.ufpb.br

Informação \& Sociedade é uma revista quadrimestral do Programa de Pós-Graduação em Ciência da Informação da Universidade Federal da Paraíba. Lançada em 1991, possui abrangência nacional e internacional e tem o objetivo de divulgar trabalhos em biblioteconomia, CI e áreas afins.

Perspectivas em Ciência da Informação,

http://www.portaldeperiodicos.eci.ufmg.br

Perspectivas em Ciência da Informação é uma revista quadrimestral da Escola de Ciência da Informação da Universidade Federal de Minas Gerais. Seu primeiro número é de 1996, em substituição à Revista da Escola de Biblioteconomia da UFMG (título original, como antes citado). Publica trabalhos em biblioteconomia, CI e áreas correlatas.

Revista ACB,

http://www. http://revista.acbsc.org.br/racb/index

Revista ACB é uma publicação semestral da Associação Catarinense de Bibliotecários. Lançada em 1996, apresenta trabalhos em biblioteconomia, CI, arquivologia e documentação, ou textos acerca de resultados e pesquisas sobre atividades concernentes ao movimento associativo (classe de bibliotecários). 
Revista Digital de Biblioteconomia e Ciência da Informação (RDBCI),

http://www. http://143.106.108.14/seer/ojs/index.php/rbci/index

RDBCI é uma revista quadrimestral do Sistema de Bibliotecas da Universidade de Campinas. Lançada em 2003, publica trabalhos da área de biblioteconomia e CI.

TransInformação,

http://www.puc-campinas.edu.br/periodicocientifico

TransInformação é uma revista especializada, com periodicidade quadrimestral, aberta a contribuições da comunidade científica nacional e internacional, editada pela Faculdade de Biblioteconomia, Centro de Ciências Humanas e Sociais Aplicadas, Pontifícia Universidade Católica de Campinas. Fundada em 1989, publica artigos que contribuem para o estudo e o desenvolvimento científico de biblioteconomia e CI em suas diversas subáreas e interfaces.

Editores do artigo: Adilson Luiz Pinto e Rafaela Paula Schmitz 